\title{
Effects of square stepping exercise in patients with sequel of cerebrovascular accident
}

\author{
Efeitos do square stepping exercise em pacientes \\ com sequelas de acidente vascular encefálico
}

\author{
Grazieli Silva Túbero $^{[a]}$, Sebastião Gobbi ${ }^{[b]}$, Camila Vieira Ligo Teixeira ${ }^{[c]}$, Jessica Rodrigues Pereira ${ }^{[d]}$, \\ Ryosuke Shigematsu ${ }^{[\mathrm{e}]}$, Ana Paula Canonici ${ }^{[\mathrm{f}]}$
}

[a] MSc candidate, Universidade Estadual Paulista "Júlio Mesquita Filho" (Unesp), Programa de Pós-Graduação em Ciências da Motricidade, Rio Claro, SP - Brazil, e-mail: grazielitubero@yahoo.com.br

[b] PhD, Universidade Estadual Paulista “Júlio Mesquita Filho" (Unesp), Programa de Pós-Graduação em Ciências da Motricidade, Rio Claro, SP - Brazil, e-mail: sgobbi@rc.unesp.br

[c] MSc, Universidade Estadual Paulista "Júlio Mesquita Filho" (Unesp), Programa de Pós-Graduação em Ciências da Motricidade, Rio Claro, SP - Brazil, e-mail: cateixeira98@yahoo.com.br

[d] MSc candidate, Universidade Estadual Paulista "Júlio Mesquita Filho" (Unesp), Programa de Pós-Graduação em Ciências da Motricidade, Rio Claro, SP - Brazil, e-mail: jpereira@rc.unesp.br

[e] PhD, Mie University, Faculty of Education, Kurimamachiya-cho Tsu, Mie - Japan, e-mail: rshige@edu.mie-u.ac.jp

[f] MSc, professor, Centro Universitário Hermínio Ometto (Uniararas), Araras, SP- Brazil, Curso de Fisioterapia, e-mail: apcanonici@bol.com.br

\section{Abstract}

Introduction: Cerebral stroke is the interruption of blood flow to the brain and can be classified into hemorrhagic and ischemic. It may result in serious body balance and cognition complications. Kinesiotherapy is a privileged means of rehabilitation. Objective: Verify the effects of Square Stepping Exercise (SSE) on cognitive functions, depressive symptoms and the body balance of cerebral stroke sequel patients. Methods: Thirteen brain stroke sequel patients were divided into two groups: SSE (SSEG $n=8$ ) and conventional physiotherapy group $(P G, n=5)$. The SSEG participated only of the SSE training protocol, while the PG participated of its physical therapy routine group, both for 4 months. They were evaluated using the Mini Mental State Examination (MMSE), the Brief Cognitive Screening Battery (BBRC), the Geriatric Depression Scale (GDS), Berg Balance Scale (BBS) and Timed Up and Go (TUG). Results: The U Mann Whitney test showed no significant differences between groups. In intragroup analysis, the Wilcoxon test showed significant improvement in global cognitive status for PG 
$(\mathrm{p}<0.042)$, and for SSEG there were positive results for verbal fluency $(\mathrm{p}<0.04)$ and in TUG for number of steps $(p<0.04)$ and the time $(p<0.02)$. Conclusion: The SSE seems to benefit dynamic balance, influencing gait agility, cognition related to verbal fluency and may have contributed to maintain other cognitive functions.

Keywords: Cerebrovascular accident. Cognition. Balance.

\section{Resumo}

Introdução: $O$ Acidente vascular encefálico (AVE) é a interrupção do fluxo de sangue para o cérebro e pode ser classificado em hemorrágico e isquêmico, podendo resultar em graves complicações do equilíbrio corporal e cognição. A cinesioterapia constitui-se em meio privilegiado de reabilitação. Objetivo: Verificar os efeitos do Square Stepping Exercise (SSE) nas funções cognitivas, nos sintomas depressivos e no equilíbrio de pacientes com sequelas de AVE. Métodos: Treze pacientes com sequelas de AVE foram alocados em dois grupos: grupo SSE (GSSE $n=8$ ) e grupo fisioterapia convencional (GF $n=5$ ). $O$ GSSE participou apenas do protocolo de treinamento do SSE, o GF participou apenas de sua rotina de fisioterapia realizada em grupo, ambos pelo período de 4 meses e avaliados por meio do Mini Exame do Estado Mental (MEEM), da Bateria Breve de Rastreio Cognitivo (BBRC), da Escala de Depressão Geriátrica (GDS), da Escala de Equilíbrio Funcional de Berg (EEFB) e do Timed Up and Go (TUG). Resultados: $O$ teste $U$ Mann Whitney não apontou diferenças significantes intergrupos. Na análise intragrupo, o teste de Wilcoxon mostrou melhora significativa no GF ( $p<$ $0,042)$ no estado cognitivo global, e no GSSE quanto à fluência verbal $(p<0,04)$ e no TUG tanto para número de passos $(p<0,04)$ quanto para tempo o $(p<0,02)$. Conclusão: O SSE parece beneficiar o equilíbrio dinâmico, fazendo com que os pacientes com sequela de AVE apresentem marcha mais ágil, a cognição no tocante à fluência verbal, bem como pode ter contribuído para a manutenção de outras funções cognitivas.

Palavras-chave: Acidente Vascular Encefálico. Funções cognitivas. Equilíbrio.

\section{Introduction}

Cerebrovascular diseases are the third cause of death in the world, coming after heart disease and cancer (1). In Brazil, studies from Lotufo (2) indicate a decrease in mortality due to cerebrovascular diseases, although it is still one of the main causes of death in our country. Among the cerebral vascular diseases, it is possible to highlight the cerebrovascular accident (CVA).

According to World Health Organization (WHO), CVA is an acute neurologic dysfunction, of vascular origin, followed by the sudden or quick occurrence of signs and symptoms related to the impairment of specific areas in the brain (3). Still, in that context, CVA, depending on the location and extension of injury, may cause neurologic deficits. The most common sequels of CVA are: motor, sensitive and visual deficits, epileptic seizures, infections, depressions, dysphagia, and alterations of cognitive functions, such as memory, praxis, language and executive functions. All of those manifestations may lead to a functional incapacity for the individual affected by CVA $(4,5,6)$.
Patients with CVA sequels generally keep the daily routine of pharmacological and non-pharmacological therapies, according to their CVA type and etiology. For the non-pharmacological therapy, physiotherapy treatment can be emphasized. It consists in restoring body functions and/or softening sequels. Nevertheless, the graphic tends to establish after some time, however, even so, patient may present enduring impairments which need physiotherapy treatment for a long period of time (7).

Literature affirms that regular participation in physical activity programs seems to have a positive influence on decrease of falls, physiologic capacity, and prevention of cognitive decrease, besides psychological and emotional benefits (8). Moreover, another study still indicates that chronic hemiplegic stroke patients with CVA sequels, through physical activity programs, presented improvement on balance, gait and cardiovascular condition (9).

Recently, Square Stepping Exercise (SEE) program was created by Shigematsu and Okura (10), with the 
main objective of improving balance of their participants, decreasing, consequently, the risk of falls. Despite of that, SSE seems to require low to moderate physical effort simultaneously with high level of cognitive functions for its performance.

Considering literature consensus about brain plasticity emphasizing that motor tasks practice induces plastic and dynamic changes (11), and studies with human beings confirm that neural reorganization can be eased when incorporating repetitive training (12). So, since SSE is a method that requires steps repetition to accomplish the proposed sequences, it may benefitiate the mentioned changes and reorganization.

Therewith, this study had the objective to verify the effects of SSE on cognitive functions, depressive symptoms and balance of patients with CVA sequels.

\section{Materials and methods}

Thirteen patients with clinical diagnostic of cerebrovascular accident (CVA), of both genres, participated of this study, with age between 50 and 80, applied for physiotherapy treatment in Clínica Escola de Fisioterapia do Centro Universitário Hermínio Ometto - Uniararas.

The recruitment was made through phone calls and patients were selected for convenience. Patients that accepted to take part of the research were distributed into the Square Stepping Exercise group (SSEG), and patients who were not willing to change their physiotherapy routine were distributed into the physiotherapy group (PG), which was already part of the clinic in Uniararas.

Some inclusion criteria were used to select patients, such as: age between 50 and 80; only one unilateral cerebrovascular lesion from less than 12 months before the intervention, verified through computed tomography or magnetic resonance images; capacity of understanding verbal instructions and capacity of deambulation without or with help of prostheses or orthoses.

Square Stepping Exercise group (SSEG) was composed by eight patients with CVA diagnoses, where five of them had right-sided hemiplegy/hemiparesis and three of them had left-sided hemiplegy/hemiparesis ( 7 men and 2 women), that participated only of the SSE training protocol. That protocol was applied three times a week, with duration of 90 minutes each session, for four months. The training was based on the usage of a "mat" $(2.5 \times 1.0 \mathrm{~m})$, partitioned into 40 small squares of $25 \mathrm{~cm}$ each, where participants should walk over it according to the step pattern showed by the researcher. Each patient repeated each sequence three times, and then started a new one. Sequences were created with forward, backward, lateral and oblique steps, and, for each sequence, the complexity of the steps combination was higher. There are 6 categories where the sequences are located according to their difficulties: Elementar, Basic, Intermediary 1, Intermediary 2, Advanced 1, and Advanced 2.

The physiotherapy group (PG) was composed by five patients with CVA diagnoses, where two of them had right-sided hemiplegy/hemiparesis and three of them had left-sided hemiplegy/hemiparesis (4 men and 1 woman), that participated only of the physiotherapy routine in group. There was one session a week, with duration of 60 minutes each, for four months. They practiced physiotherapy exercises of balance, proprioception, gait, and circuit training for lower limbs strength, according to the need of every patient.

The project was approved by the Ethic Committee of Uniararas (098/2010). For the participants, it was presented a Free Consent Term, where those which agreed in participating signed it.

For data collection, instruments were used to evaluate cognitive functions, depressive symptoms and dynamic balance of patients before and after the experimental period, such as:

Mini Mental State Examination (MMSE) $(13,14)$ has the objective of evaluating specific cognitive functions. MMSE scores may vary from zero to a maximum total of 30 .

Brief Cognitive Screening Battery (BCSB) (15, 16) includes the application of the Semantic Verbal Fluency Test (17) and the Clock Drawing Test (18) as distractors. BBRC consists in clustering many tests for cognitive evaluation, in the following sequence: test of visual perception and naming, incidental memory, immediate memory, learning, semantic verbal fluency (animal category), the clock drawing test, memory after 5 minutes and recognition.

Geriatric Depression Scale (GDS) (19) was used to evaluate depressive symptoms. It is compounded of 15 closed questions, with score from 0 to 1 for each one selected. The cutoff scores used were (20): (0 to 
5) depression absence; (6 to 10) moderate depression; and (11 to 15$)$ severe depression.

Berg Balance Scale (BBS) (21) evaluates functional balance performance in 14 common items in daily life. The maximum score reaches 56 .

Timed Up and Go Test (TUG) (22) evaluates basic functional mobility, analyzing time spent through individual to stand up from an armchair, walk a distance of 3 meters and return to the chair, as well as the number of steps necessary for the activity execution.

\section{Data analysis}

For data analysis, after verifying data normality, there were applied U-Mann Whitney test, in order to verify feasible differences between groups in pre and post moments of the experimental period, and the Wilcoxon test, in order to verify possible effect of interventions. The adopted significance level was $5 \%(\mathrm{p}<0.05)$.

\section{Results}

Thirteen patients with CVA sequels were analyzed. In SSEG, $75 \%$ of patients $(n=6)$ were male, and $25 \%$ $(n=2)$ were female, with mean age of $60.1 \pm 9.5$ and education level between $3.8 \pm 2.1$. The mean time for SSEG was of $7.5 \pm 5.7$ years. In PG, $80 \%(n=5)$ of patients were male, and $20 \%(n=1)$ were female, with mean age of $65 \pm 7.10$ and education level between $3.2 \pm 1.3$. The mean time diagnostic for $P G$ was of 4.6 \pm 4.03 years (Table 1 ).
Statistic did not indicate significant difference between groups for data of sample characterization. Neither had it indicated significant difference on the initial moment of the study, showing that the groups were similar.

In relation to global cognitive state evaluated by MMSE, results showed significant improvement only for PG ( $\mathrm{p}$ < 0.042), and SSEG obtained scores maintenance (Table 2).

With respect of instruments to measure cognitive functions observed by BBRC, statistic did not indicate significant difference in the intergroup analysis for any of the tests on pre and post experimental periods.

Analyzing intragroup behavior, Wilcoxon test showed significant difference in SSEG for Verbal Fluency $(\mathrm{p}<0.04)$ variable. For BBRC domains, results indicated scores maintenance in SSEG and PG (Table 3).

Depressive symptoms measured by GDS did not present significant improvement for both groups, but it presented a tendency of depressive symptoms improvement in SSEG ( $\mathrm{p}<0.07)$ (Table 4).

For the analyzed balance through BBS and TUG spent for steps and time, statistic did not show significant difference in intergroup analysis on pre and post moments of experimental period.

At the end of the study it was observed that both groups kept their scores for BBS. For TUG spent for steps and time, a significant improvement was observed in SSEG, being $\mathrm{p}<0.04$ e $\mathrm{p}<0.02$, respectively (Table 5). While in PG, although it was not significant, it was observed a worsening in both items, through increase of steps number and time to complete the test.

Table 1 - Mean and standard deviation results of interference variables (sex, age, education and CVA time)

\begin{tabular}{|c|c|c|c|}
\hline \multirow{2}{*}{ Variables } & SSEG $(n=8)$ & $P G(n=5)$ & \multirow{2}{*}{$\mathrm{p}$} \\
\hline & Mean \pm SD & Mean \pm SD & \\
\hline Sex & $F=2(25 \%) / M=6(75 \%)$ & $F=1(20 \%) / M=4(80 \%)$ & \\
\hline Age (years) & $60.13 \pm 9.58$ & $65 \pm 7.10$ & 0.36 \\
\hline Education (years) & $3.88 \pm 2.17$ & $3.2 \pm 1.30$ & 0.79 \\
\hline CVA time (years) & $7.50 \pm 5.71$ & $4.6 \pm 4.03$ & 0.98 \\
\hline
\end{tabular}

Note: F/M: Female and Male; SSEG: Square Stepping Exercise group; PG: Physiotherapy group.

Source: Research data. 
Table 2 - Mean and standard deviation results pre and post evaluation of SSEG and PG, in MMSE, with intragroup comparison

\begin{tabular}{|c|c|c|c|c|c|c|}
\hline & \multicolumn{2}{|c|}{ SSEG $(n=8)$} & & \multicolumn{2}{|c|}{$P G(n=5)$} & \\
\hline & PRE & POST & & PRE & POST & \\
\hline Variables & Mean \pm SD & Mean \pm SD & $p$ & Mean \pm SD & Mean \pm SD & $p$ \\
\hline MMSE & $23.1 \pm 4.5$ & $24.8 \pm 5.1$ & 0.17 & $23.8 \pm 2.9$ & $26 \pm 2.12$ & $0.042^{*}$ \\
\hline
\end{tabular}

Note: MMSE: Mini Mental State Examination; SSEG: Square Stepping Exercise Group; PG: physiotherapy group. Values of $p$ for Wilcoxon test with statistically significant difference with $p<0.05$.

Source: Research data.

Table 3 - Mean and standard deviation pre and post evaluation of SSEG and PG, in Brief Cognitive Screening Battery on the Semantic Verbal Fluency Test and the Clock Drawing Test, with intragroup comparison

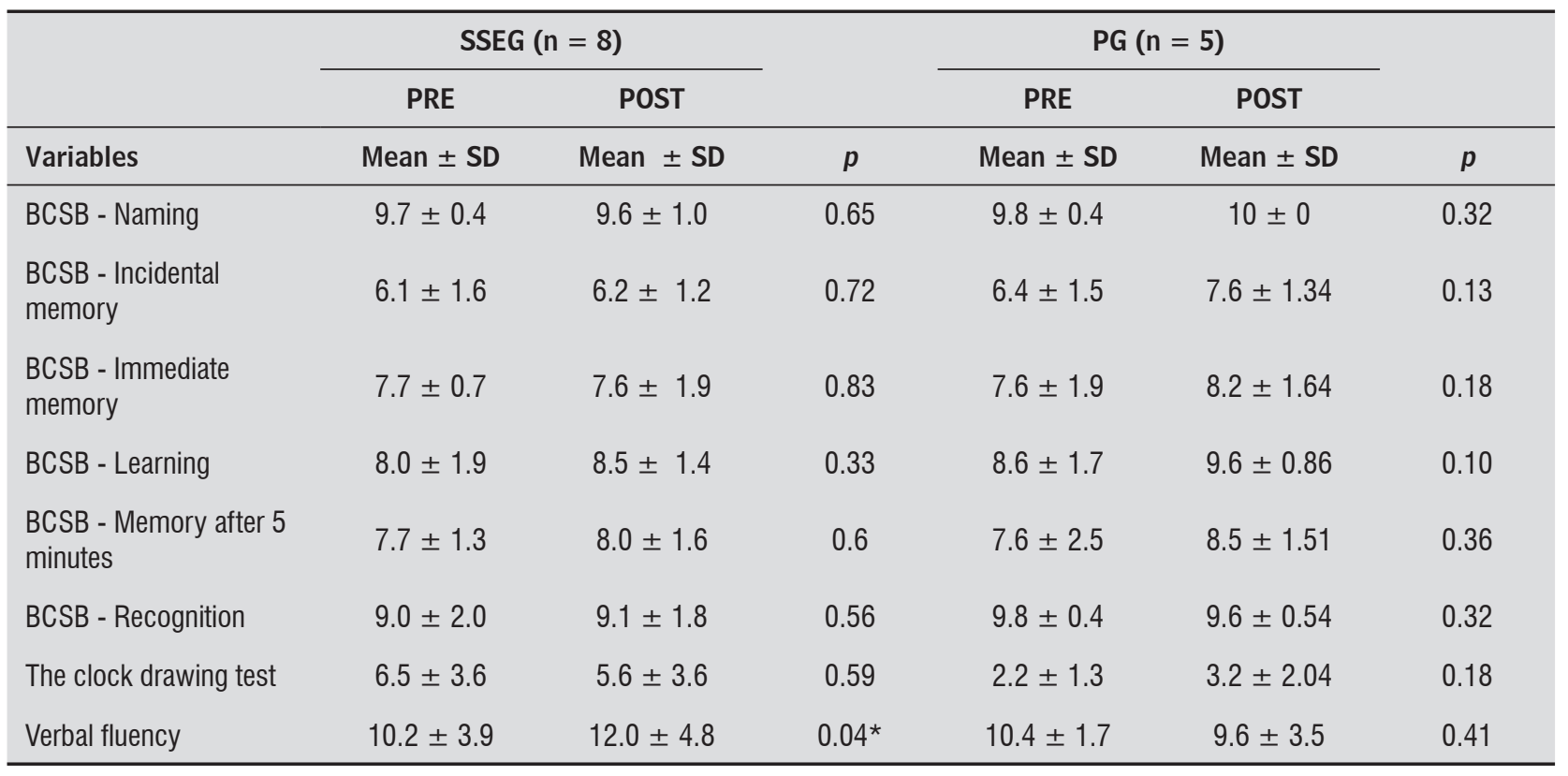

Note: BCSB: Brief Cognitive Screening Battery; SSEG: Square Stepping Exercise Group; PG: Physiotherapy Group. Values of $p$ on Wilcoxon test with statistically significant difference with $p<0.05$.

Source: Research data.

Table 4 - Mean and standard deviation results pre and post evaluation of SSEG and PG, on Geriatric Depression Scale, with intragroup comparison

\begin{tabular}{lccccccc}
\hline & \multicolumn{2}{c}{ SSEG $(\mathrm{n}=8)$} & & \multicolumn{2}{c}{ PG $(\mathrm{n}=5)$} & \\
\cline { 2 - 3 } & PRE & POST & & & PRE & POST & \\
\cline { 2 - 3 } Variables & Mean \pm SD & Mean \pm SD & $p$ & & Mean \pm SD & Mean \pm SD & $p$ \\
\hline MMSE & $23.1 \pm 4.5$ & $24.8 \pm 5.1$ & 0.17 & & $23.8 \pm 2.9$ & $26 \pm 2.12$ & $0.042^{*}$ \\
\hline
\end{tabular}

Note: GDS: Geriatric Depression Scale; SSEG: Square Stepping Exercise Group; PG: Physiotherapy group. Values of $p$ on Wilcoxon test with statistically significant difference with $p<0.05$.

Source: Research data. 
Table 5 - Mean and standard deviation results pre and post evaluation of SSEG and PG. on Berg Balance Scale and Timed Up and Go (for steps and time). With intragroup comparison

\begin{tabular}{|c|c|c|c|c|c|c|}
\hline & \multicolumn{2}{|c|}{ SSEG $(n=8)$} & & \multicolumn{2}{|c|}{$P G(n=5)$} & \\
\hline & PRE & POST & & PRE & POST & \\
\hline Variables & Mean \pm SD & Mean \pm SD & $p$ & Mean \pm SD & Mean \pm SD & $p$ \\
\hline BBS - points & $48.5 \pm 5.8$ & $50.8 \pm 3.3$ & 0.27 & $46.8 \pm 6.4$ & $46.2 \pm 7.29$ & 0.58 \\
\hline TUG- steps & $24.6 \pm 8.6$ & $22.1 \pm 6.6$ & $0.04^{*}$ & $27.6 \pm 7.4$ & $28.2 \pm 10.75$ & 0.68 \\
\hline TUG - time & $29.1 \pm 22.1$ & $21.0 \pm 10.5$ & $0.02^{*}$ & $26.2 \pm 14.3$ & $29.4 \pm 16.87$ & 0.17 \\
\hline
\end{tabular}

Note: GDS: Geriatric Depression Scale; SSEG: Square Stepping Exercise Group; PG: Physiotherapy group. Values of $p$ on Wilcoxon test with statistically significant difference with $p<0.05$.

Source: Research data.

\section{Discussion}

The present study had as main objective to verify the effects of SSE on cognitive functions, depressive symptoms, and balance of patients with sequels of CVA.

In order to reach the objective, it was compared the performance of patients with CVA sequels, who participated of different motor interventions: SSE and a physiotherapy program, for a period of four months. Though it was not found difference between groups after experimental period, there were changes on variables in each group, showing the influence of the training on verbal fluency and gait agility for patients that practiced SSE, and on global cognitive functions for patients that kept with their physiotherapy routine.

Sample was mainly of men corroborating with a study made in Sao Paulo countryside (23) and another one made in Joinville city, in which it was found greater proportion of men than women for patients affected by CVA (24).

In relation to MMSE, the education mean of groups was low, which influences on the MMSE result. The final score interpretation of MMSE is based on Brucki study (14), where there were proposed reference values with the objective of detecting possible cognitive decrease on patients. In Brazil, the most updated proposal is: 20 points for illiterates; 25 points for individuals with 1 to 4 years of education level; 26.5 points for 5 to 8 years; 28 points for 9 to 11 years; and 29 points, since 11 years of education. The average of MMSE of SSEG, at the end of the study, did not show significant difference, only scores maintenance. A study made with patients with CVA to verify the effect of a specific training of balance in chronic hemiplegic patients, MMSE was used only for sample characterization, resulting on the average of $24.5 \pm$ 3.3 points (25), similar results to SSEG. The average of MMSE of PG, at the end of the study, was $26 \pm 2.12$ points, presenting significant improvements.

After a cerebral trauma, the cognitive impairments are very common and may affect memory, attention, and association of these abilities. That episode generates a decrease of organization of thoughts, promoting a disorganization of the language process, including problems related to the way of speaking and to the sequential production of words, which may compromise the capacity of compression of written or spoken information (26). The incidence of cognitive disturbances on surviving individuals in post-CVA period varies from $12 \%$ to $56 \%(27,28)$.

Tasks of verbal fluency have been largely used to evaluate language processing and executive function. Alteration on this ability may be the result of articulatory difficulties and on mechanisms of speech initiation or semantic impoverishment. Those functions are organized on frontal, temporal and parietal lobes and alterations are also described in subcortical lesions (2). Patients with CVA sequels may present these alterations when evaluating cognitive functions of a group of aphasic and non-aphasic patients with CVA sequels, Bonini (29) observed injuries on verbal fluency variable. In our study, it was possible to observe that motor deficit interference (paresis of the dominant hand) and difficulties of verbal production are factors that harm execution of some evaluations and results interpretation. Despite this characteristic presented by our patients, the group that has the 
SSE protocol as intervention presented significant improvement on semantic verbal fluency after experimental period.

Nevertheless, it is not possible to claim that these significant improvements on cognitive aspects: verbal fluency, for the group that practiced SSE, and global cognitive state, for the physiotherapy group, occurred due to cognitive influence of training, because, as mentioned before, results on cognitive evaluations may be harmed by motor deficit and difficulty of verbal production. The fact that can be claimed is that both types of intervention promoted positive influence over their patients in these aspects, because it was observed improvement in the final result.

Another important aspect evaluated was depressive symptoms verified through GDS, which did not present significant improvement on SSEG and PG, but a tendency for improvement of depressive symptoms on SSEG. Depression is easily found in patients with CVA sequels and Parkinson's disease. It can be seen as a consequence of physical and psychosocial alterations that those pathologies can bring as part of the clinical picture. When depression is treated, it is observed an improvement on functional recovery and decrease of cognitive harm (30).

From the present study, it may be suggested that the participation in group for accomplishing the protocol of SSE contributed for a better performance of patients of SSEG. The social interaction and the participation in group through physical activities benefit emotional aspects of patients with CVA sequels, improving their autonomy and self-confidence (7). It is important to highlight that the mean score of SSEG and PG before intervention already showed depressive symptoms (20).

BBS was used to evaluate balance among patients, more specifically, the risk of falls. In the current literature, there are used many cutoff scores of BBS, varying from 36 to 52 . Belgen and colleagues (32) studied 50 patients with CVA sequels in chronic phase to evaluate risk of falls and concluded that individuals present risk of falls when BBS is lower than 52 . According to this author, in order to better discriminate patients who complain about falls and indicate risk of falls in a chronic hemiparethic population, cutoff score of 52 is the most appropriate. The initial mean scores from both groups were below 52 (48.5 \pm 5.8 for SSEG and $46.8 \pm 6.4$ for PG). And, in spite of interventions, there was no significant improvement on this test.
For TUG, used for steps and time, patients of SSEG obtained significant improvement, upgrading, therefore, gait agility. Patients of PG, though not statistically significant, worsened on both items of TUG, increasing the number of steps and time to complete the test. TUG tool for time has a strong relation with balance, gait speed and functional ability, thus it is inversely associated with functional mobility level and tendency of episodes of falls (22). The same authors profess that in elderly with neurologic pathologies, values higher than 30 seconds on TUG test are predictors of mobility deficiency and functional dependence for this population.

The published studies with SSE showed significant improvement on components of functional ability, related to lower limbs in healthy elderly $(10,32,33)$. However, it is important to emphasize that the training protocol of these studies, besides SSE sequences, included exercises with 10 minutes of warm-up, walking and stretching, specific resistance exercises for the whole body for 10 minutes, and 10 minutes of cool down exercises, such as stretching exercises. On the other side, the training protocol of SSE, in the present study, was compounded only of SSE sequences, with no other kind of exercise, with patients with neurological pathologies, CVA in this case, showing the efficiency of this training for that population.

Taking into consideration that the studied population presents important neurological injury, the fact of significant improvement and scores maintenance, at the end of the study, can be considered as an important gain for maintenance of cognitive functions, balance and non-alteration of depressive symptoms. Despite relevance of the results found in this study, it presents some limitations, once the number of participants of PG was lower compared to SSEG, also the number of sessions per week of PG was only once a week. Nevertheless, as explained in the methods, PG was compounded by patients of the clinic, being used as control group in this study.

\section{Conclusion}

SSE has a positive result for patients with CVA sequel, because it improves their dynamic balance making possible to have a more agile gait and verbal fluency, as well as a possible contributor to maintain other cognitive functions. Thus, this type of intervention has a good potential to be applied in patients that 
present some physical or neurological injury, which may constitute a new resource for rehabilitation.

\section{References}

1. Barros JEF. Acidente vascular cerebral. In: Nitrini R, Bacheschi LA. A neurologia que todo médico deve saber. São Paulo: Maltese; 1991. p. 133-47.

2. Lotufo PA. Stroke in Brazil: a neglected disease. Sao Paulo Med J. 2005;123(1):3-4.

3. World Health Organization (WHO). Cerebrovascular disorders. Geneva: WHO; 1978.

4. Mazzola D, Polece JC, Schuster RC, Oliveira SG. Perfil dos pacientes acometidos por acidente vascular encefálico assistidos na clínica de fisioterapia neurológica na universidade de Passo Fundo. RBPS. 2007; 20(1):22-7.

5. Suutuama T, Ruoppila I. Associations between cognitive functioning and physical activity in two 5-year follow-up studies of older finish persons. J Aging Phys Act. 1998;6(2):169-83.

6. Chodzko-Zajko WJ, Moore KA. Physical fitness and cognitive functioning in aging. Exerc Sport Sci Rev. 1994;22(1):195-220.

7. Costa A, Duarte E. Atividade física e a relação com a qualidade de vida, de pessoas com sequelas de acidente vascular cerebral isquêmico (AVCI). Rev Bras Ciên e Mov. 2002;10(1):47-54.

8. Nelson, H. A modified card sorting test sensitive to frontal lobes defects. Cortex. 1976;12(4):313-24

9. Michael K, Goldber AP, Treuth MS, Beans J, Normandt P, Macko RF. Progressive adaptive physical activity in stroke improves balance, gait, and fitness: preliminary results. Top Stroke Rehabil. 2009;16(2):133-9.

10. Shigematsu R, Okura T. A novel exercise for improving lower-extremity functional fitness in the elderly. Aging Clin Exp Res. 2006;18(3):242-8.

11. Fisher BE, Sullivan KJ. Activity-dependent factors affecting poststroke functional outcomes. Top Stroke Rehabil. 2001;8(3):31-44.
12. Milter W, Bauder H, Sommer M, Dettmers C, Taub E. Effects of constraint-induced movement therapy on patients with chronic motor deficits after stroke: a replication. Stroke. 1999;30(3):586-92.

13. Folstein M, Folstein S, McHugh P. "Mini-mental state". A practical method for grading the cognitive state of patients for the clinician. J Psychiatr Res. 1975; 12(3):189-98.

14. Brucki SMD, Nitrini R, Caramelli P, Bertolucci, PHF, Okamoto IH. Sugestões para o uso do mini-exame do estado mental no Brasil. Arq Neuro-Psiquiatr. 2003;61(3B):777-81.

15. Nitrini R, Lefévre B H, Mathias SS, Caramelli P, Carrilho PEM, Sauaia N, et al. Testes neuropsicológicos de aplicação simples para o diagnóstico de demência. Arq Neuro-Psiquiatr. 1994;52(4):457-65.

16. Nitrini R, Caramelli P, Herrera Júnior E, Porto CS, Charchat-Fichman H, Carthery MT, et al. Performance of illiterate and literate nondemented elderly subjects in two tests of long-term memory. J Int Neuropsychol Soc. 2004;10(4):634-8.

17. Brucki SMD, Malheiros SMF, Okamoto IV, Bertolucci PHF. Dados normativos para o teste de fluência verbal categoria animais em nosso meio. Arq NeuroPsiquiatr. 1997;55(1):56-61.

18. Sunderland T, Hill JL, Mellow AM, Lawlor BA, Gundersheimer J, Newhouse PA, et al. Clock drawing in Alzheimer's disease. A novel measure of dementia severity. 1989;37(8):725-9.

19. Yesavage J, Brink T, Lun O, Huang V, Adey N, Leirer V. Development and validation of a geriatric depression screening scale: a preliminary report. J Psychiatr Res. 1983;17(1):37-9.

20. 21. Almeida OP, Almeida SA. Short versions of the geriatric depression scale: a study of their validity for the diagnosis of a major depressive episode according to ICD-10 and DSM-IV. Int J Geriatr Psychiatry. 1999;14(10):858-65.

21. Berg KO, Wood-Dauphinées SL, Williams JI, Maki B. Measuring balance in the elderly: validation of an instrument. Can J Public Health. 1992;83(Suppl 2): S7-11. 
22. Podsiadlo D, Richardson S. The timed "Up \& Go": a test of basic functional mobility for frail elderly persons. J Am Geriatr Soc. 1991;39(2):142-8.

23. Rodrigues JE, Sá MS; Alouche S. Perfil dos pacientes acometidos por AVE tratados na clínica escola de fisioterapia da UMESP. Rev Neurocienc. 2004; 12(3):117-22.

24. Cabral NL, Longo AL, Moro CHC, Amaral CH, Kiss HC. Epidemiologia dos acidentes cerebrovasculares em Joinville, Brasil: estudo institucional. Arq NeuroPsiquiatr. 1997;55(3):357-63.

25. Scalzo PL, Zambaldi PA, Rosa DA, Souza DS, Ramos TX, Magalhães V. Efeito de um treinamento específico de equilíbrio em hemiplégicos crônicos. Rev Neurocienc. 2011;19(1):90-7.

26. Vukovic M, Vuksanovic J, Vukovic I. Comparision of the recovery pattems of language and cognitive functions in patients with post-traumatic language processing deficits and in patients with aphasia following a stroke. J Commun Disord. 2008;41(6):531-52.

27. Rabadi MH, Rabadi FM, Edelstein L, Peterson M. Cogniti vely impaired stroke patients do benefit from admission to an acute rehabilitation unit. Arch Phys Med Rehabil. 2008;89(3):441-8.

28. Glymour MM, Weuve J, Fay ME, Glass T, Berkman LF. Social ties and cognitive recovery after stroke: does social integration promote cognitive resilience? Neuroepidemiology. 2008;31(1):10-20.
29. Bonini M V. Relação entre alterações de linguagem e déficits cognitivos não linguísticos em indivíduos afásicos após acidente vascular encefálico (dissertação). São Paulo: Universidade de São Paulo; 2010.

30. Kimura M, Robinson RG, Kosier JT. Treatment of cognitive impairment after poststroke depression: a double-blind treatment trial. Stroke. 2000;31(7):1482-6.

31. Belgen B, Beninato M, Sullivan PE, Narielwalla K. The association of balance capacity and falls self-efficacy with history of falling in community-dwelling people with chronic stroke. Arch Phys Med Rehabil. 2006;87(4):554-6.

32. Shigematsu R, Okura T, Nakagaichi M, Tanaka K, Sakai T, Kitazumi, et al. Square-stepping exercise and fall risk factors in older adults: a single-blind, randomized controlled trial. J Gerontol A Biol Sci Med Sci. 2008;63(1):76-82.

33. Shigematsu R, Okura T, Sakai T, Rantanen T. Squarestepping exercise versus strength and balance training for fall risk factors. Square-stepping exercise versus strength and balance training for fall risk factors. 2008;20(1):19-24.
Received: 04/12/2013

Recebido: 12/04/2013

Approved: $11 / 16 / 2013$

Aprovado: 16/11/2013 